\title{
Nominalism and Material Plenitude
}

\author{
Uriah Kriegel \\ Res Philosophica 98 (2021): 89-112
}

\begin{abstract}
The idea of "material plenitude" has been gaining traction in recent discussions of the metaphysics of material objects. My main goal here is to show that this idea may have important dialectical implications for the metaphysics of properties - more specifically, that it provides nominalists with new resources in their attempt to reject an ontology of universals. I will recapitulate one of the main arguments against nominalism - due to David Armstrong - and show how plenitude helps the nominalist overcome the argument.
\end{abstract}

\section{Introduction}

The term "nominalism" is used for a variety of different positions in different areas of philosophy. Here I will use it as a name for the following thesis: Everything there is either (a) is a concrete particular or (b) is built out of concrete particulars. What exactly is a "concrete particular" and what is a "building relation" are complicated issues that I wish to bracket here. Informally, a concrete particular is an entity which "takes up" some space and can be wholly present in only one place at a time; paradigmatic instances include boats, flowers, and parrots. And building relations are relations that generate a single entity out of a plurality of entities in a way that does not bring something "categorically new" into the world; here the paradigm is probably mereological composition.

Given the premium ontologists put on parsimony, nominalism is highly attractive. Indeed, as far as so-called qualitative parsimony is concerned - parsimony concerning types or categories of entity - nominalism is maximally parsimonious, since it admits entities of only one ontological category. Nominalism is of course not the only one-category ontology think of Armstrong's “world of states of affairs," or Whitehead's "process ontology." But nominalism is also distinguished by the overwhelming familiarity of the entities it privileges. Speaking for myself, I run into concrete particulars all day long and have actually held concrete particulars in my own two hands. In contrast, I have never held a process or a state of affairs.

If nominalism is so attractive, why is it a minority position in contemporary ontology? There are in fact several sources of resistance to nominalism. I cannot address all 
of them here. Instead, I focus on one argument, due to David Armstrong, which seems to me (and others, though not everybody) to capture at least one important source of resistance. The basic idea may be put as follows.

The schema " $x$ is F" has many true instances. "The Statue of Liberty is verdigris" and "The statue of Liberty has mass $m$ " are just two examples (where verdigris is that peculiar light grayish-green color copper becomes as it rusts and $m$ is whatever maximally determinate mass property the Statue in fact has). What grounds, or metaphysically explains, the truth of such statements? That is, what are their truthmakers? A traditional answer appeals centrally to universals - entities that can be wholly present in different places at the same time. The truthmaker of "The Statue of Liberty has mass $m$," on this view, is the fact that a certain concrete particular, the Statue of Liberty (which is wholly present in only one place at a time), instantiates a certain universal, having mass $m$ (which is wholly present wherever something has mass $m$ ). This is a very natural view, but not one that the nominalist is entitled to, since it invokes universals. The nominalist must identify a truthmaker for "The Statue of Liberty has mass $m$ " that invokes concrete particulars exclusively. But - so goes Armstrong's argument - there is no remotely plausible way to do this.

In section 1, I lay out the argument with more precision. In section 2, I illustrate the depth of the challenge by applying it to David Lewis's "class nominalism." After a detour in sections 3-4 through recent discussions of "material plenitude," I formulate in section 5 a version of nominalism that incorporates plenitude. In section 6, I show how this version - I call it plenitudinous nominalism - provides nominalistic truthmakers for simple predicative truths like "The Statue of Liberty has mass $m$." There follows a brief interlude (section 7) on David Lewis's final view as it comes through in a posthumously published article. I close, in section 8 , by addressing wider potential concerns with plenitudinous nominalism.

Naturally, even if we accept that a certain version of nominalism can solve one problem for nominalism, that would not show that it can solve all problems for nominalism. It would show, however, that the existence of true predicative statements does not by itself rule out nominalism. To that extent, it would constitute important input into the dialectic. In future work, I intend to develop the fuller case for plenitudinous nominalism.

\section{Armstrong's Truthmaker Argument against Nominalism}

It is far from obvious just what a truthmaker is. Armstrong himself held that the truthmaker of $p$ is an entity E, such that E's existence necessitates the truth of $p$ (2004: 5). Some philosophers have argued that this is too strong, entailing, at least against certain assumptions, that all truths are necessary (Williamson 1999). But it is also possible to see 
necessitation as too weak: we expect a truthmaker to make us see why a statement is true, and necessitation is not always explanatory in this way. ${ }^{1}$ Thus some philosophers have understood truthmaking in terms of metaphysical (or "grounding") explanation: $\mathrm{E}$ is the truthmaker of $p$ iff the existence of E metaphysically explains the truth of $p$, in the sense that $p$ is true in virtue of E existing (Rodriguez-Pereyra 2002: 30, 34).

Indulging Armstrong, but not wishing to beg any questions against others, I will here require truthmakers to be both necessitating and explanatory. This would ensure that we have not weakened, but on the contrary have only strengthened, Armstrong's hand. If we can show that even in this strengthened form the truthmaker argument fails, we will have done nominalism a good service.

The result is the following argument against nominalism. Let us contract "The Statue of Liberty" into "SoL" and "has mass $m$ " into "is M." Then:

1) An adequate ontological theory must posit an entity (or entities) the existence of which both necessitates and explains the truth of "SoL is M";

2) If nominalism were right that there are only concrete particulars, there would be no entity (nor entities) the existence of which both necessitates and explains the truth of "SoL is M"; therefore,

3) Nominalism is not an adequate ontological theory.

Obviously, there are two ways to resist this argument. The "metaontological route" rejects Armstrong's truthmaker requirement (i.e., premise 1). The ontological route accepts the truthmaker requirement but insists that nominalism can meet it (contra premise 2).

The natural way to develop the metaontological objection is through the thought that while there may sometimes be no entity E the very existence of which metaphysically explains the truth of " $x$ is F," there is always an entity the character of which does. Accordingly, the only entity required to explain the truth of "SoL is M" is SoL, though it is not just the existence of SoL that is implicated in the explanation - it is also the character of SoL, what SoL is like. This response, which Armstrong (1978: 16) facetiously called "ostrich nominalism," essentially rejects Armstrong's "rules of the game" (for the latest iteration of ostrich nominalism, see Hofweber 2016: 288).

As before, I will indulge Armstrong here and grant him his "rules of the game." This is not because I want to endorse Armstrong's truthmaker methodology, but on the contrary because I am (here) disinterested in metaontological questions. I am much more interested in a distinctive first-order ontology that emerges as an elegant response to Armstrong's truthmaker argument, I want to argue, when nominalism incorporates a certain, somewhat untraditional approach to material objects. Accordingly, I will pursue the "ontological route" of rejecting premise 2 above. 
The difficulty in pursuing this approach is easy to appreciate. On its own, the sheer existence of SoL neither necessitates nor explains the truth of "SoL is M." It clearly does not necessitate the truth: loss of a small enough part would not destroy SoL, but would change its mass. SoL would then still exist, but "SoL is M" would no longer be true. In addition, the mere existence of SoL does not fully explain the truth of "SoL is M." What the sheer existence of SoL fully explains is the truth of "SoL exists." But in "SoL is M" there is some extra information, not included in "SoL exists," and there is nothing in the mere existence of SoL to explain the truth of a statement that includes this extra information. ${ }^{2}$

Another aspect of this explanatory failure is this: the truths of "SoL is M," "SoL is verdigris," and "SoL exists" are distinct explananda, and there is no reason to expect them to receive the same explanans. So SoL should not be the thing whose existence explains all of them. Sometimes there are reasons to expect a single explanans. "Phosphorus is spherical," "Hesperus is spherical," and "Hesperus is spherical or cubic" all receive the same truthmaker - for Armstrong, it is the state of affairs consisting of Venus being spherical but here there are reasons we can cite for this: the fact that "Phosphorus" and "Hesperus" co-refer and the fact that that referent is spherical-or-cubic in virtue of being spherical. But there is nothing like this in the case of "SoL is M," "SoL is verdigris," and "SoL exists." We should thus expect a distinct explanans for each of these; it should not be the same thing that explains the truth of all of them - and of every other SoL-truth to boot.

The extant literature features a number of nominalist attempts to address the problem of identifying universals-free truthmakers for such simple predicative truths - we may call it, following Van Cleve (1994), the problem of "predication without universals." Although my purpose in this paper is positive rather than destructive, I want to illustrate the severity of the problem by considering the difficulties it presented to David Lewis's class nominalism.

\section{Lewis's Nominalism and Its Discontents}

Perhaps the most straightforward version of nominalism is "class nominalism," which in addition to straightforwardness can claim for itself the virtue of having been David Lewis's view $(1983,1986)$. On this view, the truthmaker of a true statement of the form " $x$ is F" is always $x^{\prime}$ s a membership in the class of all and only Fs. Thus, what necessitates and explains the truth of "SoL is M" is SoL's membership in a class of concrete particulars, the class we would informally describe as the m-massed objects.

An immediate problem for class nominalism is that the membership relation invoked here threatens to reintroduce a universal. The same relation SoL bears to the set of $m$ massed objects it also bears to the set of statues, the set of verdigris objects, and so on; and 
it is the same relation that the horsehead in Hyde Park bears to the set of verdigris objects. It is, in all these cases, the membership relation, which thus seems to be a repeatable entity. The suspicion is that "SoL is a member of $S$ " (where $S$ is the class of all $m$-massed objects) will have to be made true by the fact that the membership universal is instantiated jointly by SoL and S. Might it be made true instead by the fact that the ordered pair (SoL, S) is a member of the set of all membership pairs? It certainly might, but as Russell (1912: 55) pointed out in a similar context, this leads immediately to an infinite regress.

Even if the class nominalist manages to render the appeal to membership harmless (perhaps in the manner of Rodriguez-Pereyra 2001), one might wonder what relevance an object's membership in a class with other objects has to the object's mass. David Armstrong presses the point forcefully (1992: 16):

[C]onsider the natural class consisting of all and only the objects having temperature $T$. Let $a$ be a member of this class. What have the other members of this class ... to do with $a$ 's temperature? After all there would appear to be a possible world where these other members do not exist, or where they exist but lack temperature $T$.

Recall that a truthmaker is supposed to explain a statement's truth. But given that an object's mass is an intrinsic affair, other $m$-massed objects would appear to be explanatorily irrelevant to the truth of "SoL has mass $m$. "

Indeed, suppose that due to a cosmic incident, all objects suddenly and instantaneously doubled in mass. Then SoL would still be a member of the same class of objects as before, but "SoL has mass $m$ " would no longer be true - it is rather "SoL has mass $2 m$ " that would.

Another issue is that the class-nominalist approach to predication is really hopeless unless class nominalists welcome concrete possibilia into their ontology - which Lewis of course did, but which not every nominalist might be keen to. We can see this by considering a pair of objections that would be quite decisive if appeal to concrete possibilia were not contemplated.

First, consider predicative truths involving coextensive predicates. All and only renates are cordates, but intuitively, what explains the truth of "Socrates is renate" is different from what explains the truth of "Socrates is cordate." On the face of it, though, class nominalism identifies the same truthmaker: the fact that Socrates is a member of class $\mathrm{C}$, the class of all and only renates/cordates. As before, the explananda are different - why should the explanans be the same? For someone like Armstrong, the explanantia are indeed different: the state of affairs of Socrates instantiating the universal of being renate in one case, the state of affairs of Socrates instantiating the universal of being cordate in the other case. These are different states of affairs, since they have a different constituent in the 
universal position. The question is whether the nominalist could also produce different explanantia here.

Secondly, consider predicative truths involving single-instance predicates. The cosmos as a whole, understood as the totality of matter, has some specific mass too. Let us suppose it is $10^{100} \mathrm{~kg}$. (The total mass of the what physicists call the "observable universe" is apparently something in the vicinity of $1.5 \times 10^{53} \mathrm{~kg}$. We do not know whether the unobservable universe is finite or infinite, but for simplicity let us suppose that it is finite and its mass is exactly $10^{100} \mathrm{~kg}$.) Then the predicate "has a mass of $10^{100} \mathrm{~kg}$ " applies to only one object - the cosmos. What makes "The cosmos has a mass of $10^{100} \mathrm{~kg}$ " true? According to class nominalism, it would be the cosmos's membership in the singleton the cosmos\}. But this membership fact seems hopelessly inadequate to the task, as it neither necessitates nor explains the truth of "The cosmos has a mass of $10^{100} \mathrm{~kg}$." After all, if the cosmos somehow lost some of its mass (or doubled it, or whatever), it would still be a member of \{the cosmos\} - but "The cosmos has a mass of $10^{100} \mathrm{~kg}$ " would be false. And how is the cosmos's membership in the cosmos\} supposed to in any way illuminate or explain the truth of "The cosmos has a mass of $10^{100} \mathrm{~kg}$," as opposed to the putative truth of "The cosmos has a mass of $2 \mathrm{~kg}$ " or indeed of "The cosmos is nice"?

These problems disappear when we construe the relevant classes as including not only actual but also merely possible objects (Lewis 1986: 50). Although the class of all actual renates is the same as the class of all actual cordates, the class of all possible renates is distinct from the class of all possible cordates. Although the set of all actual $10^{100} \mathrm{~kg}$ massed objects is just \{the cosmos\}, the set of all possible $10^{100} \mathrm{~kg}$ massed objects is much vaster. Thus the problems presented by coextensive and single-instance predications can be solved if one counts also merely possible objects. Recall, however, that for nominalists everything either is or is built out of concrete particulars. So for this option to be available to nominalists, they must construe merely possible objects as concrete particulars (or else as somehow built out of concrete particulars - unclear how that might work). Thus must class nominalists hitch their wagon to the star of concretist modal realism. This is not the place to debate the merits of concretist modal realism, but it is no secret that most contemporary metaphysicians do not endorse it. It would be disappointing news to learn that nominalism's viability is hostage to the dialectical vicissitudes of concretist modal realism.

In addition, we should keep in mind that embracing concretist modal realism does nothing to assuage the aforementioned worries for nominalism, for instance concerning the relevance of class membership to the truth of intrinsic predications.

Obviously, Lewis-style class nominalism is not the only nominalist approach to predication without universals. But at least by way of illustration, I hope the discussion in this section makes clear the severity of the difficulties nominalism faces when it tries to 
identify adequate truthmakers for even the simplest predicative truths. In the remainder of this paper, I want to present a novel approach to the problem, one that identifies certain actual concrete particulars which both necessitate and explain the truth of predicative statements. To appreciate this approach, though, I need to introduce an idea that has commanded increasing support elsewhere in contemporary metaphysics: the idea of material plenitude.

\section{Coincidence}

The Statue of Liberty is made of a certain quantity of copper. Is this lump of copper the same object as SoL, or a different one? According to one-thingism, they are the same; according to two-thingism, they are different. Most philosophers are two-thingists here. The basic reason is simply the intuition that if we flattened the lump of copper, SoL would be destroyed but the copper-lump would go on existing. This seems to show that SoL and the copper-lump - call it Cooper - have different identity and persistence conditions, and are thus distinct beings, despite coinciding perfectly in space.

Strictly speaking, all the fact that a scenario is possible in which Cooper exists but SoL does not shows is that, in that possible scenario, $\mathrm{SoL} \neq$ Cooper. The one-thingist may still insist that even though SoL $\neq$ Cooper in that counterfactual scenario, in the actual world SoL $=$ Cooper. But this requires that what is one thing in one possible world is two things in a different possible world (Gibbard 1975). It is not easy to wrap one's mind around this notion (what does "what" refer to in the locution "what is one thing in one world"?), and so it is standard in modal logic that if $x=y$ then necessarily $x=y$. Kripke (1971) famously offered a straightforward argument for this: clearly, $x=x$ holds not just contingently, but necessarily, but if $x=y$ and necessarily $x=x$, then necessarily $x=y$; so, if $x=y$, then necessarily $x=y$. This is not the place, of course, to debate the ultimate merits of "contingent identity." What I want to point out is just this: to infer two-thingism from the possibility of SoL going out of existence without Cooper going out of existence, all we have to assume is the principle of the necessity of identity. With this principle at hand, we can offer the following little argument for two-thingism:

1) We can imagine circumstances where SoL goes out of existence but Cooper does not; so,

2) Possibly, SoL $\neq$ Cooper;

3) For any $x$ and $y$, if $x=y$ then necessarily $x=y$; therefore,

4) SoL $\neq$ Cooper.

Call this the "little argument." 
Suppose then that SoL $\neq$ Cooper. How can we account for this non-identity of perfectly coincident objects? What explains this non-identity? The task is specially difficult given that SoL and Cooper are qualitatively indistinguishable: they have the same shape, the same color, the same mass, and so on. They do differ in some of their modal and temporal properties, and maybe such things as kind properties, but such differences seem to flow from their being distinct objects rather than to underlie it. As a testament to this, note that one-thingists in fact deny that SoL and Cooper differ in their modal and temporal properties; the only difference, for them, is in descriptions of the same object, with whatever modal properties it has. Thus difference in modal differences etc. cannot be the ultimate explanation, for a two-thingist, of the non-identity of SoL and Cooper. What might?

We will consider some options in a moment. But first I want to stress, for reasons I will come back to later, that looking for what explains the alleged non-identity of SoL and Cooper is by and large a separate matter from identifying what motivates believing in such non-identity in the first place. What motivates the non-identity is the little argument above, whose only independent premises are (1), the imaginability of scenarios in which Cooper exists but SoL does not, and (3), the principle of the necessity of identity. If we accept both these premises, we are more or less forced into two-thingism. Once we have accepted twothingism, we may then raise the question of what explains the non-identity of such intimately bound-up objects. It is true that the availability of an explanation would deepen our confidence in two-thingism, and that the more satisfying the explanation the deeper our conviction will go. Nonetheless, it is significant that there are reasons to believe twothingism which are independent of, and prior to, any explanation of the non-identity of SoL and Cooper. The significance of this will emerge in section 5.

What, then, might explain the non-identity of SoL and Cooper? One possibility, of course, is that the difference between them is brute and inexplicable: they are different things, and that is all there is to it. Some philosophers have argued that object identity/difference is always brute like this (e.g., Hazlett 2010: 81). On this view, nothing underlies the individuality of individuals - Socrates is one individual, Plato is another, and any other difference there might be between them presupposes this fact. If this is true of Socrates and Plato, it would presumably be true also of SoL and Cooper.

Naturally, though, we typically prefer an informative explanation, where we can have it, over brute facts. A simple explanation of SoL's alleged non-identity with Cooper might be that they have different haecceities. However else they differ, says the haecceitist, Socrates and Plato also differ in that only one of them has Socrateity, while the other has Platotude. It is this fact that ultimately underlies Socrates $\neq$ Plato. By the same token, the suggestion might go, in addition to being $m$-massed, verdigris, tall, and so on, SoL also has SoLitude, while Cooper has Coopereity instead. 
The explanatory depth of this proposed explanation is a tad disappointing: we are told that what explains the fact that SoL $\neq$ Cooper is that SoL's haecceity $\neq$ Cooper's haecceity - but then the "explanation" comes to an abrupt end. A deeper, more informative explanation is that although SoL and Cooper have all the same qualitative (non-modal, nontemporal, non-haecceistic, etc.) properties, they differ in whether they have these properties essentially or accidentally. For example, SoL has essentially its statuesque shape, whereas Cooper has that shape merely accidentally. This is why Cooper can survive the kind of dramatic change in shape that SoL cannot.

This explanation of SoL $\neq$ Cooper has its cost, insofar as it posits two ways of having properties (essentially and accidentally), but perhaps that is just the price of informativeness and explanatory depth. In any case, it is this explanation that the great majority of two-thingists have in fact adopted. Keep in mind, though, that although shared by many two-thingists, this is just an explanation of why So $\neq \neq$ Cooper, not what motivates believing that $\mathrm{SoL} \neq$ Cooper in the first place.

\section{Plenitude}

Suppose what makes SoL and Cooper distinct is that there are properties F and G, such that both SoL and Cooper are F and G, but SoL is essentially F while Cooper is accidentally F and/or Cooper is essentially $\mathrm{G}$ while SoL is accidentally G. This raises some questions. Is there also a third object, coincident with both SoL and Cooper, which has both F and G essentially? Is there a fourth one that has both $\mathrm{F}$ and $\mathrm{G}$ merely accidentally? If not, why not, and if yes, why yes? The general question here is: what are the rules for deciding which distributions of essentiality and accidentality across any collection of co-instantiated properties correspond to an object and which do not?

Such considerations lead the essentialist two-thingist to the following forced choice: either (a) provide a principle of essence-restriction, whereby some distributions of essentiality/accidentality are admissible and others are not, or (b) openly adopt a principle of plenitude, whereby more or less every logically coherent distribution of essentiality and accidentality corresponds to a numerically distinct object. (Why "more or less"? We will see momentarily.)

Out of pessimism about finding a workable principle of essence-restriction, a principle that would not be overly anthropocentric and/or uncomfortably arbitrary, many metaphysicians have recently opted for Option (b) - adopting plenitude. Recent proponents include Karen Bennett (2004), John Hawthorne (2006), Mark Johnston (2006: 697-8), Sarah-Jane Leslie (2011), Shamik Dasgupta (2018: 547-8), and Maegan Fairchild (2019). But in fact we find the plenitude thesis defended already in the 1980s, under different 
names, by Kit Fine (1982: 100, 1999: 67, 73) and Stephen Yablo (1987: 302, 310). Here is how Bennett states the thesis of plenitude (2004: 354):

[E]very region of space-time that contains an object at all contains a distinct object for every possible way of distributing 'essential' and 'accidental' over the [non-modal, non-sortal] properties actually instantiated there.

So: For any region R occupied by a concrete particular with $n$ properties, a principle of material plenitude might be expected to posit, in a first approximation, $2^{n}$ coincident material objects in R. This is only a first approximation for several reasons. First, the sort of properties that coincidents do not share (e.g., modal properties) would not go into this calculation. Second, some properties that coincidents do share (e.g., determinable properties) cannot vary in the distribution of essentiality and accidentally over them independently of the variation across other properties (e.g., maximally determinate properties) - see Bennett 2004: 357-8 and Leslie 2011: 279. Finally, some general metaphysical principles (e.g., that no object can have all its properties merely accidentally) may rule out certain specific distributions. It is a vexing question how to formulate plenitude in a completely general and principled way (Fairchild 2019). But this is not our topic here. For our purposes, it would suffice to say the following: where $k$ is the number of logically possible distributions of essentiality/accidentality ruled out by one of the above considerations (or another, for that matter), according to material plenitude (i) there are $2^{n}-k$ coincident objects in any region that contains one object with $n$ properties and (ii) $k$ is dwarfed by $2^{n}$ (it is in this context a virtue of "dwarfed" that it is so vague!).

I have mentioned plenitude's pedigree in the metaphysics of the past half century. But the truth is that plenitude has an even longer and more illustrious history within the Aristotelian tradition, where it was defended by Aristotle (Matthews 1982), Aquinas (Inman 2014), and Brentano (Kriegel 2015). In Aristotle's repeated discussions of the ontological status of such things as seated-Socrates and musical-Coriscus - referred to by Aristotle scholars as "kooky objects" (following Matthews 1982: 224) - Aristotle insists that (i) there are such entities and (ii) they are not identical with Socrates and Coriscus. They are not identical with them precisely because they differ in their identity and persistence conditions: when Socrates stops sitting, seated-Socrates goes out of existence but Socrates does not. Moreover, as far as we know there are no substantial restrictions on which accidents of Socrates could be used to generate a "Socrates-based" kooky object. This collection of claims very much points in the direction of plenitude.

Karen Bennett, who introduced the term "plenitude" as it applies in this context, does not offer a direct argument for it, and indeed does not quite endorse it, claiming that one-thingism might ultimately be more plausible (2004: 359). Rather, what she argues is that for anyone who rejects one-thingism, there is no stable position that comes short of allout plenitude. What she calls "bazillion-thingism" (356) - and we might call " $2^{n}$ - $k$-thingism" 
- is more stable than two-thingism, three-thingism, four-thingism, and so on. The reason for this, recall, is that the prospects for identifying a position in-between one-thingism and allout plenitude that would be neither arbitrary nor anthropocentric are dim.

We may, of course, put together this consideration with the little argument from section 3 to produce a "big argument" whose conclusion is plenitude. We do this by adding the following to the little argument:

5) Either (i) one-thingism, (ii) plenitude, or (iii) something in-between;

6) (i) is inconsistent with 4;

7) (iii) is infected with arbitrariness and/or anthropomorphism; therefore,

8) (ii), i.e., plenitude.

This is an argument by elimination for plenitude, which takes the respective problems of one-thingism and intermediate positions between one-thingism and plenitude as grounds for eliminating them, leaving only plenitude standing.

It is not my purpose here to evaluate the big argument for plenitude. I only want to make two claims about this argument: first, it captures schematically the standard reason plenitudinists have for their view, and second, this reason to go plenitudinist should appeal to the nominalist just as much as to anybody else. It is this last point that I want to belabor next. Of the three premises the big argument adds to the small argument, only 7 is an independent, substantial (non-trivial) claim. Thus anyone who accepts premises 1, 3, and 7 of the big argument finds herself with a strong reason to adopt plenitude. What I want to argue next is that all three of these premises are available to a nominalist just as much as to an anti-nominalist.

\section{Plenitudinous Nominalism}

Suppose two ontologists chat over coffee about whether they should be one- or twothingists. Should it make any difference to their conversation whether one, both, or neither is a nominalist? The topic - whether a statue and the copper it is made of are one or two objects - seems entirely orthogonal to their commitments over the existence of universals, states of affairs, and so on. As long as both believe that there are material objects, they can debate the question about SoL and Cooper. It is unclear what input into the dialectic might the existence of universals make.

The case for two-thingism starts with the simple pretheoretic intuition that in some situations which we can easily conceive, and which do not seem to involve any hidden incoherence, SoL would go out of existence but Cooper would not. Since this intuition is altogether pretheoretic, we should not expect one's theoretical commitments regarding the 
existence of universals - an entirely separate matter anyway - to affect one's inclination to share the intuition. As noted in section 3, this intuition, when endorsed, needs only to be supplemented with the principle of the necessity of identity to yield two-thingism. And the case for the necessity of identity, too, is something the nominalist has just as much reason to accept as anybody else. Recall Kripke's straightforward argument for the necessity of identity: it featured only quantifiers, identity, and variables ranging over individual objects; it did not feature any predicates. So, no part of this argument depends for its plausibility on some idea problematic for a nominalist. Again, then, one's commitment to nominalism should not have any effect on one's attraction to the necessity of identity. Therefore: the little argument from section 3 should be as seductive to the nominalist as it is to an antinominalist or an agnostic.

It is true that in explaining the non-identity of SoL and Cooper, the nominalist could not appeal to properties or to ways objects have them. So the most common account of the non-identity of SoL and Cooper, the account in terms of which properties are had essentially and which accidentally, is unavailable to the nominalist. It is important to keep in mind, however, that while this is a nice explanation of the non-identity of SoL and Cooper, it is not what gives us the original motivation for believing in non-identity. Even if essentialism turns out to be false, such that it is not the case that there are two ways for objects to have properties, we would still have ample reason to posit two distinct objects there. Indeed, it would be the same reason, namely, that we can imagine circumstances in which SoL goes out of existence but Cooper does not (and identity is necessary). We would then have to come up with some other account of the non-identity of SoL and Cooper.

This is the predicament the nominalist is in: one must come up with an alternative account of this non-identity - an account, in fact, that does not mention properties at all. Most naturally, the nominalist could treat this non-identity as brute: SoL is one thing, Cooper is another, and that is all there is to it. Such appeal to brutal individuation is not going to be embarrassing to nominalists, since arguably they are committed to it regardless. For consider: nominalists should be able to say, with the essentialist and everybody else, that Socrates and Plato are two distinct objects. But no nominalist would account for this in terms of the differences between Socrates's and Plato's properties. When countenancing properties at all, the nominalist explains property-identity and -difference in terms of object-identity and -difference, not the other way round. And furthermore, there is no other kind of entity E such that the nominalist could ground object identity/difference in E identity/difference, as that would cast $\mathrm{E}$ as more fundamental than objects - whereas for the nominalist objects are the ungrounded grounds of reality. So, it is only natural for the nominalist to treat the individuation of objects as ultimate - something we cannot "get underneath."3 
In other words, it is plausible that in any one-category ontology, the entities of the one fundamental category must be individuated brutally, for precisely this reason. Since nominalism is a one-category ontology in which individual objects are the one fundamental category, we should expect nominalism to embrace brutal individuation of individual objects. So the nominalist would treat even Socrates and Plato as brutally non-identical, and could (should?) then do the same with SoL and Cooper: they are two different things, and that is all there is to it.

As we have seen in section 4, from two-thingism to material plenitude the step is relatively short. It is based on the contention that it is just very difficult to identify a stable position intermediate between one-thingism and all-out plenitude, that is, to formulate a principle of essence-restriction that does not rely on arbitrary or anthropocentric distinctions. Here too, there is no reason why a nominalist should not feel the force of this consideration. To be clear, my point right now is not that the plenitudinist is right that there is no stable position in-between one-thingism and plenitude. It is only that whether or not that is so is independent of whether concrete particulars individuate by essential properties, by haecceities, brutally, or otherwise. What provides the original motivation for skepticism about a stable intermediary position between one-thingism and plenitude is not the claim that properties can be had either essentially or accidentally; it is the claim that any such intermediary position would be guilty of inadmissible arbitrariness and/or anthropomorphism. Again, this claim is something that a nominalist can be impressed with just as much as anybody else.

The point I have been trying to make so far in this section is this. Although proponents of plenitude often work within an essentialist framework for object individuation - work with it so tightly, in fact, that they typically formulate plenitude in essentialist terms - this essentialist view is neither (a) the only possible account of object individuation nor (b) the original source of motivation for plenitude. To expand on (a): It is not the only possible account, because as noted, objects may individuate by haecceities or brutally (and there are other views of object individuation as well). For reasons we have seen, nominalists are more or less compelled to adopt brutal individuation of objects. So this is what a nominalist would likely do who wished to adopt plenitude. To expand now on (b): the essentialist view is not what originally motivates plenitude, because as noted, the original motivation comes from premises (1), (3), and (7) in the big argument. That is, it comes from the joint dialectical weight of (i) the intuition that there are possible scenarios where a material object goes out of existence but its matter does not, (ii) the principle of the necessity of identity, and (iii) the difficulty of finding a principled, stable, non-arbitrary, non-anthropomorphizing position in-between one-thingism and plenitude. All three points are available to the nominalist. For they do not presuppose essentialism. Essentialism shows up only later in the story, as part of a potential account of the thus-motivated non-identity of many coincidents. 
It is true, I have granted, that the availability of an explanation or account often deepens our confidence in philosophical claims motivated by independent considerations. To that extent, the essentialist explanation of the non-identity of coincidents should make a plenitudinist extra confident. Still, its non-availability should not make the plenitudinist unconfident, since it is not what motivates plenitude in the first place. And this means that there is strong motivation to adopt plenitude that a nominalist can appreciate.

Suppose the nominalist does adopt plenitude, positing in the region where SoL stands a bewildering multitude of perfectly colocated objects. Using the Aristotelian naming scheme, we might say that in addition to SoL, there are in this region also $m$-massed-SoL, verdigris-SoL, 93-meter-tall-SoL, and so on. An essentialist who posited these objects would characterize them as follows: $m$-massed-SoL is the concrete particular which has essentially all the properties that SoL has essentially but also has essentially one property that SoL has accidentally, namely, the property of having mass $m$; verdigris-SoL is the concrete particular which has essentially all the properties that SoL has essentially but also has essentially one property that SoL has accidentally, namely, the property of being verdigris; and so on. This essentialist characterization is unavailable to the nominalist, adverting as it does to properties. Nonetheless, our nominalist posits the exact same objects, with the exact same identity and persistence conditions. It is just that differences among these objects' identity and persistence conditions are treated here as primitive, as something we cannot get underneath or explain. This is not some ad hoc position our nominalist wheels in to buttress a desire to go plenitudinist: brutal individuation of concrete particulars is part and parcel of an ontology that recognizes only concrete particulars as fundamental entities.

On the emerging ontological view, ours is a world of massively colocated concrete particulars. The world is made up entirely of concrete particulars, but there are many more of those than "folk ontology" recognizes. I call this view plenitudinous nominalism. I find it an intriguing ontology, but more importantly, I now want to show, it provides satisfactory nominalistic truthmakers for simple predicative truths like "SoL is M."

\section{Plenitudinous Nominalism and the Truthmaker Argument}

I have suggested that nominalists have a reason to embrace plenitude, namely, the same reason anybody has to do so. But do nominalists have a reason to embrace plenitude specifically in their capacity as nominalists? That is, is there anything a nominalist stands to gain qua nominalist from doing so? In this section, I want to argue that plenitude helps the nominalist solve the problem of predication without universals, that is, helps provide nominalistic truthmakers for simple predications like "SoL is M." 
The thought behind the truthmaker argument, recall, is that there must be something the very existence of which necessitates and explains the truth of "SoL is M," and while the existence of SoL necessitates and fully explains the truth of "SoL exists," it neither necessitates nor fully explains the truth of "SoL is M," which has some extra information in it clearly not mentioned in "SoL exists." For Armstrong, what necessitates (and, we may add, also explains) the truth of "SoL is M" is the existence of the state of affairs of SoL-being-M, and this state of affairs is not a concrete particular, if only because it has a universal for a constituent.

Plenitudinist nominalism offers a new approach to this problem. The basic idea is this: it is not the existence of SoL that necessitates and explains the truth of "SoL has mass $m$," but the existence of $m$-massed-SoL. Because, and so long as, $m$-massed-SoL exists, "SoL has mass $m$ " is true. If and when $m$-massed-SoL goes out of existence, "SoL has mass $m$ " would become false, as nothing would ground its truth. This is the suggestion; now let us see why it is plausible.

As noted in section 1, the existence of SoL does not necessitate the truth of "SoL has mass $m$," because SoL's existence is consistent with SoL losing some of its mass, hence consistent with the falsity of "SoL has mass $m$." In contrast, the existence of $m$-massed-SoL is inconsistent with SoL losing (or gaining) any mass, since $m$-massed-SoL is precisely that concrete particular which coincides with SoL but would go out of existence if SoL were to change in mass. The existence of $m$-massed-SoL is thus inconsistent with the falsity of "SoL has mass m." It necessitates the truth of "SoL has mass $m$. ."

In addition, the existence of $m$-massed-SoL fully explains the truth of "SoL has mass $m$. ." We noted that SoL's existence explains only the truth of "SoL exists," which lacks some information present in "SoL has mass $m$." However, what $m$-massed-SoL's existence explains fully is, in the first instance, the truth of " $m$-massed-SoL exists." The latter appears to recapture the information lost in "SoL exists" but present in "SoL has mass $m$." This is not because " $m$-massed-SoL" alludes to SoL's mass; " $m$-massed-SoL" is a proper name and does not allude to anything (except illicitly, winkingly, through my choice of a suggestive label!). Rather, what does the explaining here is the nature - or perhaps just: the identity and persistence conditions - of the object thereby named. Indeed, it is because the name " $m$ massed-SoL" winks suggestively at the right identity and persistence conditions that I have chosen it to name the relevant object. But it is the nature of the object, as reflected in its identity and persistence conditions, that fully explain why "SoL has mass $m$ " is guaranteed to be true so long as that object exists.

One somewhat traditional way to think of this is as follows. The existence of $m$ massed-SoL straightforwardly explains the truth " $m$-massed-SoL exists." Arguably, now, " $m$ massed-SoL exists" is a legitimate paraphrase of "SoL has mass $m$," since they non- 
incidentally have the same truth conditions. Now, insofar as the truth of " $m$-massed-SoL exists" is explained by some entity E, and " $m$-massed-SoL exists" paraphrases "SoL has mass $m$," we should consider that E also explains the truth of "SoL has mass $m$." And so it would appear that $m$-massed-SoL's existence explains the truth of "SoL has mass $m$."

I conclude that plenitudinous nominalism manages to provide suitable truthmakers for simple predicative truths. Interestingly, it manages to do so while avoiding the difficulties we saw with class nominalism's attempt to do the same. A central problem with class nominalism was its apparent appeal to a (presumably repeatable) membership relation; the proposed truthmaker of "SoL has mass $m$ " being the fact that SoL is a member of the class of all and only $m$-massed things. Plenitudinous nominalism, in contrast, makes no appeal to classes, nor therefore to membership in them. In fact, it appeals to nothing but one concrete particular as the truthmaker of "SoL has mass $m$. ." This is the gold standard for nominalism.

Also significant is the fact that in plenitudinous nominalism no other entity is involved in making true an intrinsic predication such as "has mass $m$." As we saw, for class nominalism the truthmaker of "SoL has mass $m$ " is SoL's relation to a certain class of objects, whereas an object's mass is intrinsic to it and it is unclear what relevance any other object has to whether " $x$ has such-and-such mass" is true. As James Van Cleve has argued, friends of universals are guilty of a similar irregularity, finding a truthmaker for "SoL has mass $m$ " in SoL's relation to a certain universal, namely, $m$-mass-ness. This, notes Van Cleve, "make[s] what is intrinsic to objects consist in a relation to something else" (1994: 582). In contrast, in plenitudinous nominalism the truthmaker of "SoL has mass $m$ " is just a certain individual, $m$-massed-SoL, and any relations this individual may or may not bear to anything else are entirely immaterial.

Most crucially, no possibilia are invoked by plenitudinous nominalism. Such objects as $m$-massed-SoL and verdigris-SoL inhabit comfortably the actual world - you can see them next time you visit New York. And such objects suffice to provide adequate truthmakers for coextensive and single-instance predications. The truthmaker of "The cosmos has a mass of $10^{100} \mathrm{~kg}$ " would be the object, coincident with the cosmos, that we may call " $10^{100} \mathrm{~kg}$-massed-cosmos." As for "Socrates is renate" and "Socrates is cordate," according to plenitudinous nominalism the truthmaker of "Socrates is renate" is renateSocrates, while the truthmaker of "Socrates is cordate" is cordate-Socrates. Importantly, positing two different coincidents here - renate-Socrates and cordate-Socrates - is not an ad hoc move tailored to generate the right number of truthmakers. The plenitudinous nominalist is justified in treating renate-Socrates and cordate-Socrates as different because there are two separate identity and persistence conditions for objects to "inhabit" here: if Socrates lost his kidneys, renate-Socrates would go out of existence, but cordate-Socrates would not. 
This, then, is the novel nominalist approach to predication without universals that I have promised. It relies on a new version of nominalism, one which combines nominalism's "world of concrete particulars" with a plenitude of coincident concrete particulars. Note well: I have argued here neither for nominalism nor for material plenitude. My goal has been modest: to point out the coherence of a version of nominalism, obtained by integrating into it a plenitude of colocated concrete particulars, that has the resources to provide truthmakers which both necessitate and fully explain the truth of predicative statements of the form " $x$ is F."

I mentioned at the opening that overcoming one problem does not a full case for nominalism make. Plenitudinous nominalism faces at least three further kinds of challenge: handling statements of the form " $x$ is F" featuring objects and predicates from more problematic domains (e.g., mathematical objects, relational predicates); handling other types of statements (notably of truth-functional and quantificational form); satisfying desiderata not pertaining to the provision of truthmakers (e.g., fitting a conception of the world suggested by fundamental science). There are also various decision points for plenitude nominalists, for instance on the question of whether some concrete particulars are more fundamental than others, and in particular, whether some coincidents are more fundamental than others.

Obviously, spelling out the full case for plenitudinist nominalism, identifying its various versions, and choosing which might be the most plausible, is not a task for a single paper. Here my goal has been modest: to motivate the idea that nominalists should take seriously the option of incorporating material plenitude into their ontology, as providing particularly promising resources for addressing the fairly foundational question of what, in a world devoid of universals, makes true simple predicative statements.

\section{Interlude: Lewis on His Deathbed}

In a paper published two years after his death, Lewis (2003) floated a new approach to predication without universals. The approach is striking because it follows the same reasoning we do, but veering off at a crucial juncture because material plenitude is not contemplated seriously. Considering a black cat named Long, Lewis writes this about the truthmaker of "Long is black" (2003: 30):

Imagine something, call it Long qua black, that is very like Long in most ways but differs from him in essence. Long is accidentally black, and might have been striped, orange all over, or even green. Long qua black, however, is essentially black. . Long qua black, if there were such a thing, would be a truthmaker for the truth that Long is black. 
So far, the approach is identical to ours. The only difference is that the object we would name "black-Long," using the Aristotelian naming scheme for kooky objects, is called by Lewis "Long-qua-black" (which in fact echoes Kit Fine's 1982 naming scheme in his own defense of plenitude).

To end up with plenitudinous nominalism, Lewis would only need to adopt our view about the relationship between Long and black-Long, that is, the view that they are coincident but numerically distinct objects. But that is not in fact what Lewis does (2003: 31):

I deny that Long qua black is a novel and peculiar sort of thing. Long qua black is none other than Long himself. . Long qua black is Long, yet the two of them have different essences. How can this one thing, Long qua black/Long, be essentially black and also be only accidentally black? My answer, of course, is that he has different essences under different counterpart relations.

Bracketing the technicalities, what Lewis is doing here is insisting on one-thingism about coincidents and wheeling in the apparatus of his concretist modal realism to make sense of the thought-experimental scenarios that push us away from one-thingism.

If we have to lean either on material plenitude or on concretist modal realism to make sense of predication without universals, I think it would be far more modest to appeal to plenitude (more on this below). For this reason, I would recommend to those who want to make the world safe for nominalism to do so by incorporating material plenitude into their ontology rather than concretist modal realism. That is, I would recommend the adoption of plenitudinous nominalism. I close now with a defense of plenitudinous nominalism against certain objections or doubts that are likely to occur to the reader.

\section{Is the Cost Too High?}

One might understandably resist plenitudinist nominalism on the grounds that it is somehow extravagant. It ought to be embarrassing to nominalists, constitutionally proud as they are of their taste for "desert landscapes," that they must resort to kooky objects to provide truthmakers for simple everyday truths. They are called kooky for a reason, after all - and there are so many of them! This reaction is understandable, but I want to argue that not much of it survives close scrutiny.

Start with the notion of parsimony. It is customary to distinguish between qualitative and quantitative parsimony: the former is a matter of positing as few types of entity as possible, the latter as few token entities as possible. Some metaphysicians (e.g., Lewis 1986) have argued that quantitative parsimony has no role to play in metaphysical theorizing: ontologists may reasonably debate whether there are strawberries or only particles arranged strawberry-wise, but just how many token strawberries or token particles there 
might be is not the ontologist's business. Other metaphysicians (e.g., Nolan 1997) have claimed that quantitative parsimony does have a role to play in metaphysical theorizing. Still, it is quite clear that in metaphysics qualitative parsimony is more theoretically valuable than quantitative. And this is significant, because as a one-category ontology, plenitudinous nominalism is maximally qualitatively parsimonious. Its alleged sins are against quantitative parsimony.

More interestingly, it is not clear that plenitudinous nominalism is as quantitatively profligate as all that. Suppose we shunned kooky objects such as $m$-massed-SoL and grounded the truth of "SoL is M" in a state of affairs consisting of SoL's instantiation of a universal of $m$-massed-ness. We would save ourselves a large quantity of token concrete particulars, but would presumably incur just as many token states of affairs: $m$-massed-SoL would no longer be part of our ontology, but the state of affairs of SoL-being-m-massed would (and with it SoL and the property of being $m$-massed, incidentally). More generally, a state-of-affairs ontology posits forsooth just as many token entities as plenitudinous nominalism; it is just that one's plentiful tokens are states of affairs while the other's are concrete particulars. So at least as compared to a standard state-of-affairs ontology, plenitudinous nominalism fares quite well even on the quantitative-parsimony front. ${ }^{4}$

It also fares well as compared to other versions of nominalism. As we have seen, many nominalists are forced to embrace concrete possibilia to handle coextensive and single-instance predications. Clearly, there are many more merely possible objects than kooky objects, if only because the latter are a proper subset of the former (even if you deny that there is an object just like Socrates but essentially seated, it is hard to see why there could not be such an object). It is of course perfectly coherent for a nominalist to reject both possibilia and kooky objects. But the question is whether any such nominalist can provide adequate truthmakers for truths of the form " $x$ is F." Obviously, if this is possible, then plenitudinous nominalism is de trop. But if it turns out that a viable nominalism must appeal to either possibilia or kooky objects, then appealing to kooky objects is far more parsimonious and more conservative.

So much for the parsimony concern. As regards the concern about the kookiness of kooky objects, here too it is useful to put things in perspective. First of all, contemporary metaphysics has found it difficult to avoid oddities in the ontology of material objects. Certainly concrete possibilia are extraordinarily strange. But more interestingly, many strange objects have become orthodox in contemporary metaphysics, even outside the context of trying to defend a nominalistic ontology. Thus, many embrace mereological universalism, and so posit such concrete particulars as the fusion of SoL, the moon, and my left index finger. In comparison, $m$-massed-SoL is not that weird. Certainly it is unclear why we should frown on material plenitude while showing so much tolerance for unbridled mereological composition. The two doctrines are at bottom rather similar, and similarly 
motivated (Fairchild 2020: 2-3): just as there appears to be no non-arbitrary way to rule in some putative composites and rule out others, so there appears to be no non-arbitrary way to rule in some putative coincidents but rule out others. ${ }^{5}$ What softens the blow with all these unusual entities is that, as concrete particulars, they are the kind of thing with which we have familiarity.

Furthermore, we must ask ourselves whether something like the state of affairs of SoL being $m$-massed is any less odd, on reflection, than the kooky object $m$-massed-SoL. The state of affairs is not just the co-occurrence of SoL and being $m$-massed: something must "glue" them together into a state of affairs. That is, there is also the instantiation of $m$ massed-ness by SoL. And the nature of instantiation, the "metaphysical glue" that turns objects and properties (or relations) into states of affairs, is a renowned conundrum. On pain of Bradley's regress, it cannot be understood as any ordinary relation. ${ }^{6}$ It must be some je ne sais quoi that no one has yet managed to understand. Armstrong himself spent the better part of a lifetime circling this conundrum, without ever reaching satisfaction. For most of his career, he referred to that which holds together SoL and $m$-massed-ness within the relevant state of affairs as a "non-relational tie." But notwithstanding the appellation, what this tie ties are after all two numerically distinct entities, and it is unclear what content the notion of relation is supposed to have that goes beyond the linking of two separate entities (cf. Van Cleve 1994: 583). There are other approaches to instantiation, of course, but the philosophical world as a whole has reached little satisfaction in this area. It is thus a major asset of plenitudinous nominalism that it allows us to avoid altogether the veritable can of worms that is instantiation/metaphysical glue.

One central source of instinctive resistance to nominalism, I suspect, comes from the subject-predicate structure of our language. This structure inclines us to see reality as structured in a parallel way, comprising concrete particulars denoted by subject terms and universals denoted by predicate terms, perhaps held together by whatever the copula stands for. But on reflection, we should probably resist the biasing effect of these linguistic facts. If nominalism is true, then reality is but a vast collection of concrete particulars, and any language that reflected accurately that reality would have to consist in nothing but an enormous collection of proper names. Such a language would be just as unlearnable and useless in everyday life as a monetary system that had one bill for $\$ 16.37$, one bill for $\$ 16.38$, one for $\$ 16.39$, and so on for every possible price some good or service might have. In both cases, a practical system requires a compositional structure featuring a limited collection of recombinable items. But reality itself owes nothing to our representational goals and limitations: $\$ 1, \$ 5, \$ 10, \$ 20$, and $\$ 50$ is no more ontologically privileged a collection of prices than $\$ 16.37, \$ 16.38$, and $\$ 16.39$; and likewise, Socrates, Plato, and Aristotle is no more ontologically privileged a collection of objects than seated-Socrates, entertaining-Plato, and wise-Aristotle. 
The point here is that to represent reality we need to use a compositional language featuring a subject-predicate structure whether or not reality is comprised of objects-cumproperty structures ("states of affairs"). That is, our statements, true statements included, have to be syntactically structured regardless of whether their worldly truthmakers are correspondingly ontologically structured. Accordingly, we should resist the temptation to infer, from the fact that our language is so structured, that reality is similarly structured.

To see just how unnatural it is for us to think of the world nominalistically, consider how natural it is to raise the following objection. It is all very nice that Verdigris-SoL exists, but "SoL is verdigris" is about SoL, not some other object colocated with it. Why should a truth about SoL (especially an intrinsic truth) be explained by a different object, one that coincides with SoL but is numerically distinct from it? The plenitudinous nominalist must of course insist that ultimately all you do when you utter "SoL is verdigris" is assert the existence of a certain individual, so the distinction between what a statement is "about," on the one hand, and what comment it makes about what it is about, on the other, is a superficial feature of language due entirely to the practical pressures driving languagedesign; or more precisely, all there is in the world to make true such a statement is the existence of a specific concrete particular, Verdigris-SoL. Clearly, this way of understanding what we do when we assert "SoL is verdigris," or what in the world corresponds to whatever we think we are doing in asserting "SoL is verdigris," is completely foreign and unnatural to us.

Indeed, there are legitimate questions about exactly which of the many coincidents is the lawful referent of natural-language names such as "the Statue of Liberty" and "Socrates." The labeling system we have been using - whereby one coincident gets a simple, straightforward name like "Socrates," while all others get derivative-sounding names like "Greek-Socrates" and "seated-Socrates" - suggests that there is a fact of the matter about which among the many coincidents is the real, honest-to-goodness Socrates. In reality, while a version of plenitude is epistemically possible that would single out a unique lawful referent of "Socrates," a more realistic version would allow quite a few - probably very many - coincidents with a legitimate claim to be the referent of "Socrates." On this view, there may be a number of more-or-less "equally good" eligible referents of "Socrates," with natural language infected by widespread referential indeterminacy. Elsewhere, I have argued precisely for this view (Kriegel 2019, but see already Bennett 2004: 361 and Leslie 2011: 281). From this perspective, it would really be more cautious to start with such names as "object-qua-mortal," "object-qua-snubnosed," "object-qua-teacher-of-Plato," "object-qua-mortal-snubnosed-teacher-of-Plato," and so on - and then address separately the question of which among these may lay a claim to co-refer with the natural-language name "Socrates." 
At the end of the day, incredulity at kooky objects may persist. Of course, such incredulity should greet all versions of plenitude, not just nominalist ones. The last thing I want to say about this is to repeat that entities foreign to "folk ontology" are par for the course in metaphysics. It is arguably part of the raison d'être of metaphysics, as a thriving intellectual discipline, that everybody seems to be stuck with some entities in their metaphysical system that folk ontology does not recognize, or finds it hard to render ultimately intelligible. If folk ontology provided us with a perfectly intelligible and unproblematic picture of reality, the exercise of metaphysics would not survive 2500 years of ardent application. Kooky objects admittedly claim their own oddity. But a one-category ontology with kooky objects aplenty also has great attraction: in its beauty and simplicity, it responsibly stays within the bounds of the actual world, and avoids the structural mysteries of states of affairs, while managing to provide adequate truthmakers for true predicative statements. ${ }^{7}$

\section{References}

- David M. Armstrong. 1978. Universals and Scientific Realism. Cambridge: Cambridge University Press.

- David M. Armstrong. 1992. "Properties.” In Language, Truth, and Ontology, edited by Kevin Mulligan, 160-172. Dordrecht: Kluwer.

- David M. Armstrong. 1997. A World of States of Affairs. Cambridge: Cambridge University Press.

- Karen Bennett. 2004. "Spatio-Temporal Coincidence and the Grounding Problem.” Philosophical Studies 118: 339-371.

- F. H. Bradley. 1893. Appearance and Reality. London: Swan Sonnenschein.

- Shamik Dasgupta. 2018. "Essentialism and the Nonidentity Problem." Philosophy and Phenomenological Research 96: 540-570.

- Maegan Fairchild. 2019. “The Barest Flutter of the Smallest Leaf: Understanding Material Plenitude." Philosophical Review 128: 143-178.

- Maegan Fairchild. 2020. "Varieties of Plenitude." Philosophy Compass 15: 1-11. DOI: https://doi.org/10.1111/phc3.12654

- Kit Fine. 1982. "Acts, Events and Things.” In Sprache Und Ontologie, edited by Werner Leinfellner, Eric Kraemer, and Jeffrey Schank, 97-105. Vienna: Holder-Pichler-Tempsky.

- Kit Fine. 1999. "Things and Their Parts.” Midwest Studies in Philosophy 23: 61-74.

- Allan Gibbard. 1975. “Contingent Identity.” Journal of Philosophical Logic 4: 187-221.

- John Hawthorne. 2006. “Plenitude, Convention, and Ontology.” In John Hawthorne, Metaphysical Essays, 53-70 0xford and New York: Oxford University Press.

- Allan Hazlett. 2010. "Brutal Individuation.” In New Waves in Metaphysics, edited by Allan Hazlett, 7290. Basingstoke: Palgrave-Macmillan

- Thomas Hofweber. 2016. Ontology and the Ambitions of Metaphysics. Oxford: Oxford University Press. 
- Ross Inman. 2014. "Neo-Aristotelian Plenitude." Philosophical Studies 168: 583-597.

- Mark Johnston. 2006. "Hylomorphism." Journal of Philosophy 109: 652-698.

- Uriah Kriegel. 2015. “Thought and Thing: Brentano's Reism as Truthmaker Nominalism.” Philosophy and Phenomenological Research 91: 153-180.

- Uriah Kriegel. 2019. “Essentialist Plenitude and the Semantics of Proper Names.” Metaphysics 2: 1625 .

- Saul Kripke. 1971. “Identity and Necessity.” In Identity and Individuation, by Milton K. Munitz, 135164. New York: New York University Press.

- Sarah-Jane Leslie. 2011. "Essentialism, Plenitude, and Paradox." Philosophical Perspectives 25: 277296.

- Lewis, D.K. 1983. "New Work for a Theory of Universals." Australasian Journal of Philosophy 61: 343377.

- David K. Lewis. 1986. On the Plurality of Worlds. Oxford: Blackwell.

- David K. Lewis. 1991. Parts of Classes. Oxford: Blackwell.

- David K. Lewis. 2003. "Things Qua Truthmakers." In Real Metaphysics, edited by Hallvard Lillehammer and Gonzalo Rodriguez-Pereyra, 25-38. London and New York: Routledge.

- Gareth Matthews. 1982. “Accidental Unities.” In Language and Logos, edited by Malcolm Schofield and Martha C. Nussbaum, 223-240. Cambridge: Cambridge University Press.

- Daniel Nolan. 1997. "Quantitative Parsimony." British Journal for the Philosophy of Science 48: 329343.

- Huw Price. 2011. Naturalism without Mirrors. Oxford: Oxford University Press.

- Gonzalo Rodriguez-Pereyra. 2001. "Resemblance Nominalism and Russell's Regress." Australasian Journal of Philosophy 79: 395-408.

- Gonzalo Rodriguez-Pereyra. 2002. Resemblance Nominalism. Oxford: Clarendon Press.

- Bertrand Russell. 1912. The Problems of Philosophy. Oxford: Oxford University Press, 2001.

- James Van Cleve. 1994. "Predication without Universals? A Fling with Ostrich Nominalism." Philosophy and Phenomenological Research 54: 577-590.

- Stephen Yablo. 1987. "Identity, Essence, and Indiscernibility." Journal of Philosophy 84: 293-314.

\footnotetext{
${ }^{1}$ On most accounts of necessitation, the fact that Jimmy is either round or not round necessitates the fact that Jimmy is blue - but obviously it does not explain it. And according to "type-B materialism," physical truths necessitate phenomenal truths without closing the "explanatory gap" between them; this too would involve a non-explanatory necessitation.

2 The extra information generates a statement in some sense richer than "SoL exists," such that what grounds the truth of the richer statement cannot be just the existence of SoL. In saying that a statement $S_{1}$ is "in some sense richer" than some $S_{2}$, I mean that $S_{1}$ says more than is said by $S_{2}$.

${ }^{3}$ There is a complication here worth flagging. A nominalist could also treat some concrete particulars as ontologically dependent on, grounded in or reduced to, other concrete particulars. Only the latter would this nominalist treat as fundamental - these might be, for instance, the subatomic particles. In that case, the individuation of the non-fundamental concrete particulars could be explained in terms of the fundamental concrete particulars. It would then be brutal individuation. But the individuation of the fundamental concrete particulars would still be brutal. I will ignore this complication in the main text.
} 
${ }^{4}$ There may admittedly be an intuition that concrete particulars, in their considerable substantiality, weigh more heavily in one's "ontological credit score" than the flighty entities that are properties and states of affairs. But what is this intuition really saying? It seems to be saying that concrete particulars are somehow "more real" than properties and states of affairs. There are many ways to approach the question of what such a claim might mean, but in any case (plenitudinous) nominalism vindicates the idea of privileged reality in concrete particulars.

${ }^{5}$ Also: just as the threat of vague composition of ordinary macroscopic objects motivates positing a plenitude of composites, with semantic indecision in natural language as to which among them is picked out (see Lewis 1991), so the prospects of vague identity and persistence conditions may motivate a plenitude of coincidents, with similar semantic indecision (see Leslie 2011).

${ }^{6}$ Bradley (1893) argued that construing the metaphysical glue between object and property as an ordinary relation would just raise the question what glues together the object, property, and relation. The answer "a second-order glue," if unpacked of some other relation, would launch us on a regress.

7 This work was supported by the French National Research Agency's grant ANR-17-EURE-0017, as well as by grant 675415 of the European Union's Horizon 2020 Research and Innovation program. For comments on an earlier draft, I am grateful to Ben Blumson and Thomas Hofweber. I have also benefited from presenting parts of the paper at Saint Louis University, The University of Konstanz, and the University of Neuchatel. I thank the audiences there, in particular Gregory Beabout, Susan Brower-Toland, Claudio Calosi, Jonathan Jacobs, Olivier Massin, Anne Meylan, Joe Salerno, Maria Scarpati, Wolfgang Spohn, and Eleanore Stump. 